\title{
Applying the DMAIC Approach for Promoting Quality \\ of Services in Islamic Azad University
}

\author{
Raissi, Sadigh
}

\author{
Eslami Farsani, Reza
}

\section{Islamic Azad University, Tehran South Branch}

\section{Abstract:}

Do you know your customers precisely? Do you document the voice of your customers correctly? Is your process capable of meeting your customer requirements? Have your nonconformities been near to the ground? World-class organizations are these questions of their enterprise and implement active programs to drive process capability throughout the organization and share the results internally through higher efficiency and with their customers through higher quality products and services. Achieve the DMAIC approach for your quality improvement programs in educational systems. Through this paper, some fundamental concept on educational quality control system delivered, DMAIC approach described and customized for Islamic Azad (IA) University, Tehran South Branch which could help university managers to provide more problems solving climate in their universities through using a never ending continuous improvement cycle. This approach could be applied for other universities to help devise creative and imaginative solutions to present problems, and could help researchers to spot opportunities that might otherwise miss.

Keywords: Voice of customer, Quality management system, Problem solving tools, DMAIC, Six Sigma,

\section{Introduction}

Since the early 1990s, Six Sigma has been initiated using statistical tools and techniques in business, transactional, and manufacturing processes [1]]. It has been proven to be successful in technology, screening process reducing costs, improving 
cycle times, eliminating defects and nonconformities, raising customer satisfaction, and significantly increasing efficiency. The effectiveness of Six Sigma to a large extent depends on its statistical techniques of defining, measuring, analyzing, improving, and controlling the critical processes. For recent advances in statistical quality techniques, the readers are recommended to refer to Tsung and Shi [2]], Tsung et al. [3]], Tsung [44]], and Tsung and Apley [[5]].

Six Sigma is a simple, unique, proven and lasting approach to improving our business performance based on:

- Alignment of the customer, strategy, processes and people

- $\quad$ Big, measurable business results

- Selective, but broad deployment of advanced quality and statistical tools

A Simple Approach to Breakthrough Performance is:

The right projects + The right people + The right roadmap and tools + The right support

$$
=\text { The right results }
$$

The five core phases of the Six-Sigma approach are also referred to as the DMAIC (Define opportunities, Measure performance, Analyze opportunity, Improve performance, Control performance) approach [[6]].

The generation of new customized ideas is a key to opening up the outlook for inventive knowledge procreation, so any approach that helps this procedure is welcome and valuable, but modern life engaged on complexity and to be creative may be easy or difficult depending on the amount of familiarity to their relevant efficient methods and climate within the working area. In order to trust knowledge procreation and to facilitate the innovation climate or atmosphere we have to introduce on all aspects, which influence on the existence of creative environments and nurturing of innovation within universities and research and development organizations. This paper proposes the DMAIC methodology to improve quality in higher educational systems through motivating the creative environments. This approach especially customized for Islamic Azad University (IAU), Tehran South Branch which could help managers to provide more problems solving climate through using a never ending continuous improvement cycle.

\section{Fundamentals of the DMAIC approach for quality improvement}

As previously said, Six Sigma methodology utilize DMAIC phases to improve quality by reducing the nonconformities. The details of these phases are as follows ${ }^{[6]}$ : In the define phase, the specific problem is identified, and the project goals and deliverables are defined. In the measure phase, a review of the types of measurement systems and their key features is included. The nature and properties of data collection must be thoroughly understood by companies. In the analyze phase, specific statistical 
methods and tools are used to isolate the key pieces of information that are important to explaining the number of defects. In the improve phase, the key factors that cause the problem are discovered. In the control phase, the processes that create the product or service are controlled and monitored continuously in order to ensure that the problem will not occur again. The elements of this never ending cycle showed in Fig 1 .

- Define - Understand the problem and limit scope, stating the problem in measurable and actionable terms

- Measure - Quantify the results of the process, measuring the variation of the performance data of the problem

- Analyze - Understand the causes of variation, finding the sources of variation to the performance data

- Improve - Determine how to best reduce variation (And don't forget to implement the improvements), eliminating or enhancing the highest drivers of the performance data variation

- Control -Measure results of the Fig 1: The DMAIC never new process to ensure that the ending cycle improvements have occurred and benefits are realized, establishing controls to manage the gains of the problem solution

In order to implement such problem solving discipline chase the following four step guides: 


\section{A) Select the Right Projects}

- Clarify big picture using strategic plan

- Establish function/area productivity baseline

- Prioritize projects based on value, resources required, timing

- Select key projects with leadership buy-in

- Check accountability: business and personal

B) Select and Train the Right People

- Ensure the right Leadership and ownership

- Develop a training plan

- Dedicate time for training and application

- Ensure the right support resources are available

C) Develop and Implement Improvement Plans

- Measure process

- Analyze process

- Improve process

- Control process

D) Manage for Excellence in Operations

- Stay focused

- Frequently review progress and remove barriers

- Check real business impact

- Continuously communicate progress

- Link to performance management and R\&R

E) Sustain the Gains

- Implement effective control plans

- Conduct regular training focused on the process

- Review the system effectiveness quarterly

- Continually identify and launch new projects

\section{The necessity for applying DMAIC in universities}

The DMAIC is a philosophy and system for continuously improving the services and/or products offered to customers. It can help university's managers to provide better service to its primary customers that are students and professors. The continuous improvement focus is a fundamental way of fulfilling the accountability requirements common to educational reform.

Operating a no-fear system and freedom environments of thinking for generating of new ideas with a focus on continuous growth and improvement offers more 
excitement and challenge to students and professors than a "good-enough" learning environment can provide [[7]].

This paper tends to give an overview to implement DMAIC in my university and other higher educational systems alternatively, in order to enrich higher educational programs. I believe that implementing this approach in educational systems is a timely tool, which must be clearly understood, adopted and implemented in right manner.

Nowadays, all systems try to deploy their activities based on an old impression said "the customer is king". Every organization has customer. There are two types of customers, one is internal and the other is external. The external customer is the person who purchases the product or service. Universities have a variety of customers. Students take courses, consume meals, sleep in residence halls, reading journals and books, and receive services from computer networks, libraries, laboratories, workshops and other services for which they pay tuition and fees. The student certainly fits the definition of the word customer. Parents, employer, community, the state government, and the society at large constitute the external clients On the other hand; the internal customer uses the products provided by the other groups. Teacher, non-academic staff, principal, manager and managing committee form the internal clients. The businesses and professions that employ the graduates are also external customers [[8]]. They seriously look for employing efficient and dynamic graduates. In generally speaking, the society is another external customer of higher educational systems. All generation need to promote their life style based on knowledge procreated through research activities in universities. All higher educational managers are responsible to hear these voices of customers and they should plan their activities in right manner to reach to the ultimate level of customer satisfactions. This shows that each and every work group is associated with the value of the product being made for the customer. This would lead all managers and academic members to attain right knowledge about the voice of customer (customer's needs and wants) and let them work accordingly.

The customer's needs have to be accurately determined and this is an important aspect of quality control. The knowledge of the customer's needs should be attained in the initial stages rather than later because it would save both time and investment. There would be a time saving and this will ultimately lead to a fair profit.

The top management of universities should develop documentations on their voice of customers in quantitative methods and their strategic plan to achieve them through specified time intervals. They should determine the answer to this question "Does the university have a clear, customer-focused mission statement and a functioning process for divisions and/or departments translating this statement into exit outcomes for graduates?" If the answer is "no", that problem must be addressed with local, state, national, and employer standards [[9]]. These standards should emphasize developing students' abilities to solve real-life problems rather than just memorizing subject matter. The latter does not represent quality for either students or professors.

\section{Conclusion:}


The DMAIC could be a philosophy and system for continuously improving the higher educational programs. It can help a university's top managers to provide better service for its primary customers say students and Parents, employers, community, the state government, and the society as a group of the secondary external customers. Continuous improvement focus of DMAIC is a fundamental way of fulfilling the accountability requirements common to educational reform. Operating a no-fear higher educational system with a focus on continuous growth and improvement offers more excitement and challenge to students and professors than a "good-enough" learning environment can provide. In macro view points, applying such approach could act as engine of knowledge procreation and the consequence of such system could facilitate learning environment and satisfying all university's customers.

In order to properly applying of the referred tools, the following five points are advised:

(a) Implement a real free thinking climate for knowledge provocation.

(b) Support professors and researchers effectively.

(c) Document voice of customers quantitatively.

(d) The most important factors that needs to be controlled carefully should be defined as a critical-to-quality characteristic that needs to be controlled in a very precise way by responsible managers.

(e) Introduce all professors on every voice of customers. 


\section{References}

[1] - Tong J. P. C., Tsung F., Yen B. P. C., (2004), A DMAIC approach to printed circuit board quality improvement, International Journal of Advanced Manufacturing Technology, 23: 523-531.

[2] - Tsung F, Shi J, (1999), Integrated design of run-to-run PID controller and SPC monitoring for process disturbance rejection, IIE Transaction, 31:517-527.

[3] - Tsung F, Shi J, Wu CFJ (1999), Joint monitoring of PID-controlled processes. Journal of Quality Technology, 31:275-285.

[4] - Tsung F, (2000), Statistical monitoring and diagnosis of automatic controlled processes using dynamic PCA. International Journal of Production Research, 38:625637.

[5] - Tsung F, Apley DW, (2002), The dynamic T-squared chart for monitoring feedback controlled processes. IIE Transaction, 34:1043-1054.

[6] - Harry M, Schroeder R, (2000), Six Sigma: the breakthrough management strategy revolutionizing the world's top corporations, Doubleday, New York.

[7] - Raissi, S., Eslami, R., (2005), Creativity Management Tools as Engine of Knowledge Procreation, Quarterly Scientific Journal of Management, Vol. 2, No. 3, IAU, Firoozkuh Branch.

[8] - Raissi, S., Javid, N., (2004), How by applying TQM, higher educational programs enriches?, The 1st international congress in quality management of educational systems, 14, 15 and 16 April 2004, Rabat, Morocco. 
[9] - Raissi, S., (2006), A Conceptual Benchmarking Model for Quality Management in "IA" University, The 3rd international congress in quality management of educational systems, 24, 25 and 26 April 2006, Rabat, Morocco. 